\title{
Micro-Implanted-Anchorage Safety: Cortical Bone Thickness in the Maxillary Posterior Region of Skeletal Class II Malocclusion
}

\author{
Seguridad en el Micro-implante de Anclaje: Espesor del Hueso Cortical en la \\ Región Posterior del Maxilar en Maloclusión de Clase Esquelética Tipo II
}

\author{
Shi-Feng Li ${ }^{1}$; Fan-Yu Xu²; Mei-Rong Xue²; Xiu-Ping Wu²; Hyo-Sang Park ${ }^{1} \&$ Li Bing $^{2}$
}

\begin{abstract}
LI, S. F.; XU, F. Y.; XUE, M. R.; WU, X. P.; PARK, H. S. \& BING, L. Micro-implanted-anchorage safety: cortical bone thickness in the maxillary posterior region of skeletal class II malocclusion. Int. J. Morphol., 36(3):1002-1006, 2018.

SUMMARY: Cone Beam Computed Tomography (CBCT) measurement of cortical bone thickness and implantation angle in the maxillary posterior region was used to provide reference for the safety of Micro-Implanted-Anchorage (MIA) implantation in skeletal class II malocclusion. Twenty samples of CBCT images were collected from orthodontics patients (ages, 12-40 years) in Shanxi Medical University Stomatological Hospital, the thickness of cortical bone was measured at $45^{\circ}, 60^{\circ}$ and $90^{\circ}$ from the alveolar crest, being at 4 $\mathrm{mm}, 6 \mathrm{~mm}$ and $8 \mathrm{~mm}$, respectively. SPSS17.0 statistical software was used to analyze the data, and the one-way ANOVA and LSD method were compared. There was a significant difference in the thickness of the cortical bone obtained by implanting MIA at the same height of different angle $(\mathrm{P} \leq 0.05)$. The greater the inclination angle of the implanted MIA, the thicker the cortical bone. Also, the higher the implant site, the thicker the cortical bone thickness. Finally, the greater the thickness of the cortical bone in the maxillary posterior region of skeletal class II malocclusion, the greater the thickness of the cortical bone. At the same implantation height, implanted MIA with a tilt angle of $45^{\circ}$ to $60^{\circ}, 90^{\circ}$ to obtain the best cortical bone thickness.
\end{abstract}

KEY WORDS: Orthodontics; Skeletal class II malocclusion; Cortical bone; Micro-Implanted-Anchorage; Implantation angle; CBCT.

\section{INTRODUCTION}

In recent years, with the continuous development of Micro-Implanted-Anchorage (MIA) materials and technology, MIA in the use of orthodontic increasingly common (Topouzelis \& Tsaousoglou, 2012; Sivakumar \& Sivakumar, 2014; Khan et al., 2016). Skeletal class II malocclusion patients after removal of premolars, through the MIA retracting anterior teeth to achieve the effect of treatment (Gandhi et al., 2017; Wu et al., 2017). The initial stability of the microscrew implantis closely related to the thickness of the surrounding cortical bone. Studies have shown that the thickness of the cortical bone is at least 1 $\mathrm{mm}$ to achieve good results. MIA implantation location and the angle of the different, the thickness of the bone cortical bone will be different, and thus affect the stability of microscrewimplant (Jasoria et al., 2013; Kalarickal et al., 2014). When the implantation site for the oblique bone surface (such as zygomatic alveolar crest, retromolar pad, external oblique ridge, etc.), the implanting nails may slide along the periosteum within the mucous membrane, without entering the cortical bone and slipping off. Incorrect implantation angle can cause the cortical thickness to be too small and cause the MIA to fall off. Therefore, the choice of appropriate implantation site and implantation angle is an important factor affecting the success of MIA. In this study, CBCT measurements of cortical bone thickness at different angles of different height in the maxillary posterior region, which provided a reference for the safety of MIA implantation in Skeletal class II malocclusion.

\footnotetext{
${ }^{1}$ School of Dentistry, Kyungpook National University, Daegu, Korea.

${ }^{2}$ Stomatology Hospital, Shanxi Medical University, Taiyuan, China. FUNDING

Shanxi Province International Science and Technology Cooperation Project(China-Korea), No.2015081030;

Shanxi Province returned overseas students research funding projects, No.2015-053.
} 


\section{MATERIAL AND METHOD}

Materials selection. CBCT images of 20 patients (10 males and 10 females) were selected from September 2016 to August 2017 in the Department of Radiology, Shanxi Medical University Stomatological Hospital. Inclusion criteria: 1) ages, 18-40 years; 2) skeletal class II malocclusion; 3) ANB $\geq 4.7$; 4) maxillary dentition complete (except for the third molar). Exclusion criteria: 1) history of cleft lip and palate, orthodontic treatment or trauma; 2) oral and maxillofacial deformities and other systemic diseases affecting oral and maxillofacial development; 3 ) maxillary sinus lesions such as cysts, tumors and so on; 4) maxillary sinus floor height less than $8 \mathrm{~mm}$.

Instruments and software. Oral and craniofacial CT (KAVO, German); Invivo 5.0 software; SPSS17.0 software.

Acquisition of CBCT image data. The maxilla was scanned with KAVO 3D eXamVision CBCT, and the scan data was converted to DICOM format.
Three-dimensional image reconstruction. The CBCT scan data was introduced into the In vivo 5 analysis software in a DICOM 3.0 standard file for multi-level reconstruction with a thickness of $0.25 \mathrm{~mm}$ layer, including reconstruction and 3D surface reconstruction. Adjust the sagittal plane, the coronal plane and the cross section so that the horizontal observation line and the vertical observation line pass through the alveolar crest and divide the apical area (Fig.1).

Measurement index. The distance from the alveolar crest $4 \mathrm{~mm}, 6 \mathrm{~mm}, 8 \mathrm{~mm}$ identified as fixed point (Fig. 2); 1) thickness of the cortical bone and its maximum bone mass at the angle of $45^{\circ}, 60^{\circ}$ and $90^{\circ}$, respectively, on the three fixations (Fig. 3); 2) distance between the alveolar crest and the maxillary sinus floor. All measurements were measured by the same person every 2 weeks, a total of three times, and the results were averaged.

Statistical Analysis. SPSS17.0 statistical software was used to analyze the data, and the one-way ANOVA and LSD method were compared.
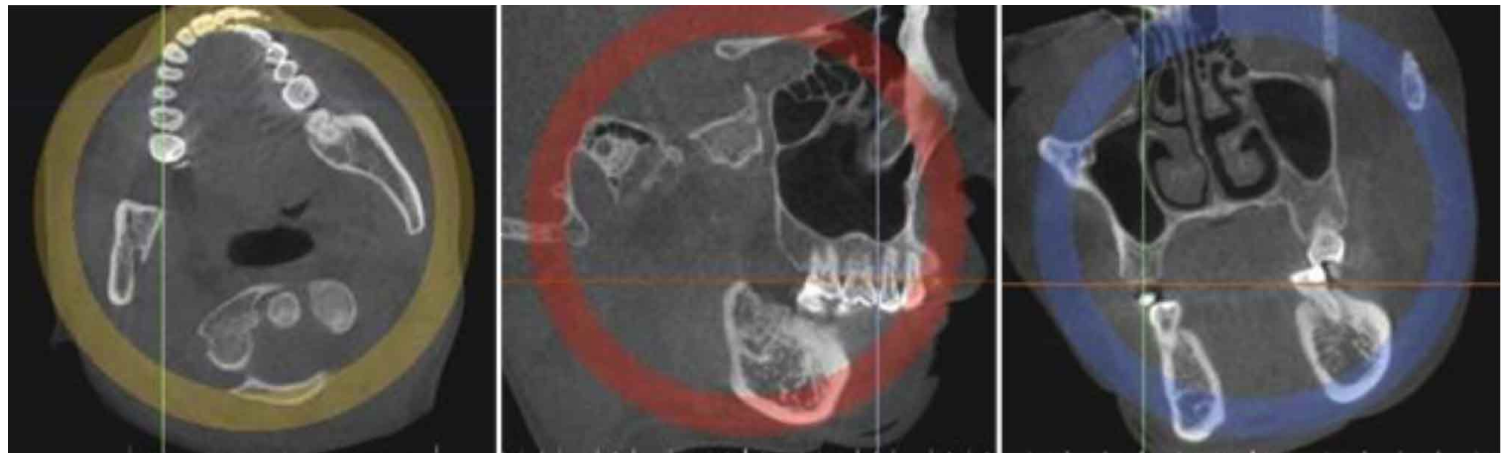

Fig. 1. Three-dimensional image reconstruction axial (left),Sagittal (middle), coronal (right).

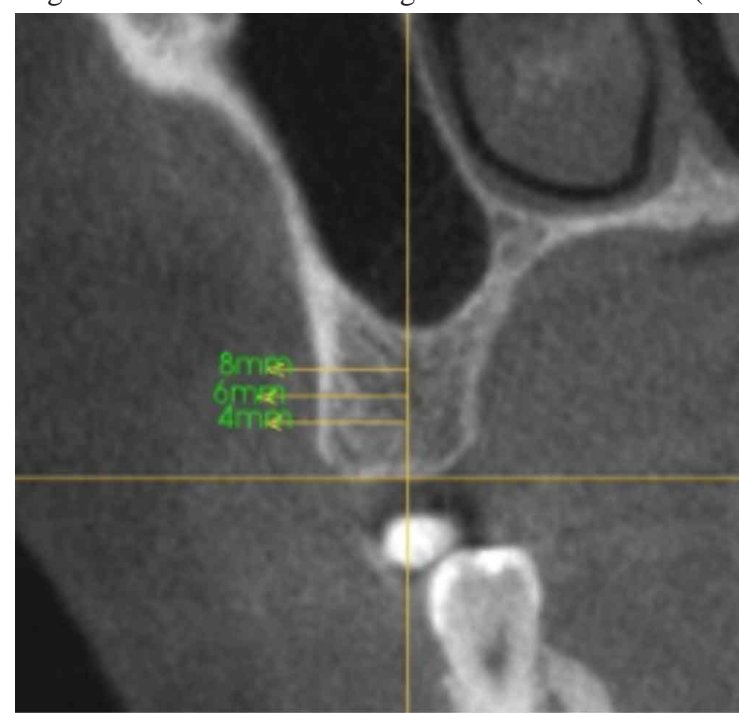

Fig. 2. From the alveolar crest $4 \mathrm{~mm}, 6 \mathrm{~mm}, 8 \mathrm{~mm}$ schematic.

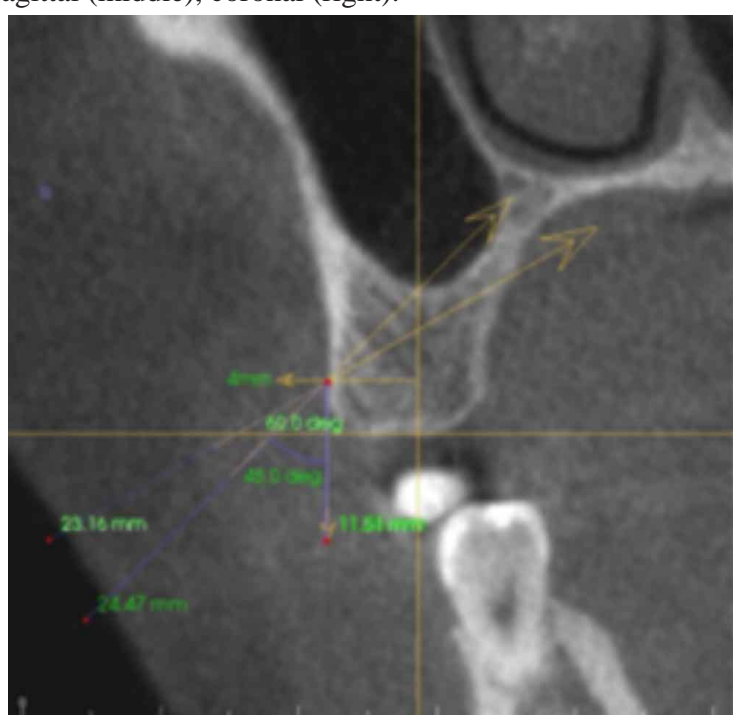

Fig. 3. The same location of different angles of cortical thickness measurement diagram. 


\section{RESULTS}

There was a significant difference in the thickness of the cortical bone obtained by implanting MIA at the different height and different angles, it has statistical significance $(\mathrm{P}$ $<0.05$ ). At the same height, the greater the inclination angle of the implanted MIA, the thicker the cortical bone (I >II > III). There was a significant difference in the thickness of cortical bone obtained by implanting MIA at the same angle of different heights, it has statistical significance $(\mathrm{P}<0.05)$, the higher the implant site, the thicker the cortical bone thickness $\mathrm{a}<\mathrm{b}<\mathrm{c})($ Table I).
There was not a significant difference in the maximum bone mass obtained by implanting MIA at the same height and different angles, it has statistical significance $(\mathrm{P}<0.05)$. There was not a significant difference in the maximum bone mass obtained by implanting MIA at the same angle of different heights $(\mathrm{P}<0.05)$ (Table II).

Annotations: I, II, and III represent the $45^{\circ}, 60^{\circ}, 90^{\circ}$ angle of implanted MIA; a, b, c, represent the distance from the alveolar crest distance of $4 \mathrm{~mm}, 6 \mathrm{~mm}, 8 \mathrm{~mm}$;* represent a significant difference between groups $(\mathrm{P}<0.05)$.

Table I. Measurement of cortical thickness at different angles from alveolar crest at different heights ( $\mathrm{mm}, \mathrm{X} \pm \mathrm{Sn}=20)$

\begin{tabular}{cccccc}
\hline Location & I & II & III & F & P \\
\hline a & $2.10 \pm 0.42$ & $1.82 \pm 0.22$ & $1.33 \pm 0.21$ & 16.495 & $0.000^{*}$ \\
b & $2.48 \pm 0.35$ & $2.09 \pm 0.22$ & $1.52 \pm 0.19$ & 27.888 & $0.000^{*}$ \\
c & $2.74 \pm 0.33$ & $2.30 \pm 0.17$ & $1.96 \pm 0.10$ & 30.055 & $0.002^{*}$ \\
F & 7.434 & 13.111 & 31.778 & & \\
P & $0.003^{*}$ & $0.002^{*}$ & $0.000^{*}$ & \\
\hline
\end{tabular}

Table II. Safety measurements at different angles at different altitudes ( $\mathrm{mm}, \mathrm{X} \pm \mathrm{Sn}=20)$

\begin{tabular}{cccccc}
\hline Location & I & II & III & F & P \\
\hline a & $12.76 \pm 3.12$ & $13.73 \pm 3.15$ & $11.18 \pm 1.93$ & $12.21 \pm 2.30$ & 1.655 \\
b & $11.28 \pm 3.83$ & $13.10 \pm 3.59$ & $12.50 \pm 1.86$ & 1.271 & 0.139 \\
c & $9.46 \pm 4.87$ & $10.55 \pm 4.27$ & 1.145 & 0.228 \\
F & 1.700 & 2.069 & 0.333 & \\
P & 0.202 & 0.146 & & \\
\hline
\end{tabular}

\section{DISCUSSION}

With the widespread application of MIA technology, reasonable and personalized implantation of micro-implant nails are more and more orthodontist attentive. The implantation of microscrew implant requires a certain thickness of cortical bone support, and the implantation site and angle are different, resulting in a different thickness of the cortical bone, which in turn affects the stability of MIA (Lee et al., 2014; Maino et al., 2016; AntoszewskaSmith et al., 2017). From the safety point of view that the implantion position from the junction cemento-enamel farther, the thicker the cortical bone, the greater the risk. The most suitable implant site is from the junction cemento-enamel $2-4 \mathrm{~mm}$, implanted angle greater than $45^{\circ}$ to avoid touch the maxillary sinus. Some scholars from the perspective of reducing micro-implant inflammation around the point of view, that the maxillary posterior region of the microscrew implant should be in mucogingival junction or attached gingival, that is, from the alveolar crestabout $4 \mathrm{~mm}$ (Tenenbaum \& Tenenbaum, 1986; Melsen et al., 2015; Lee et al., 2017). Some scholars measured the cortical thickness of the maxillary posterior root tip to the alveolar crest at $2 \mathrm{~mm}, 4 \mathrm{~mm}, 6 \mathrm{~mm}, 8 \mathrm{~mm}$ level, and suggested that the cortical thicker from the alveolar crest can obtain good initial stability, but there is no combination of angle to measure (Duran et al., 2015). In this study, the thickness of cortical bone and bone was measured at $45^{\circ}$, $60^{\circ}$ and $90^{\circ}$ from the three sites of the alveolar crest at 4 $\mathrm{mm}, 6 \mathrm{~mm}$ and $8 \mathrm{~mm}$, respectively. Measurement of cortical bone thickness and implantation angle in the maxillary posterior region was used to provide reference for the safety of MIAimplantation in skeletal class II malocclusion. 
Table I shows that at the same implant angle, the thickness of the cortical bone at $8 \mathrm{~mm}$ was significantly greater than at $6 \mathrm{~mm}$ and $4 \mathrm{~mm}$. That is, the alveolar crest at the top of the cortical bone is thin, away from the alveolar crest near the base bone bone cortex thicker. The maxillary and mandibular first molars of 43 adult patients were measured from the alveolar crest respectively in the direction of the apical direction. It was found that the thicker the cortical thickness was obtained from the alveolar crest, the greater the mandible than the maxilla (Ono et al., 2008). For the implanted area of patients with adequate bone, can choose to stay away from the alveolar crest site to implant MIA. At the same implantation height, implanted MIA with a tilt angle of $45^{\circ}$ to $60^{\circ}, 90^{\circ}$ to obtain the best cortical bone thickness. Laursen et al. (2013) experimented with the implantation of MIA from $90^{\circ}$ to $45^{\circ}$, and the contact area of the cortical bone increased by $47 \%$. The results are consistent with this study (Laursen et al.). Wilmes et al. (2008) from the perspective of torque, displacement stability of the study, also reached a similar point of view. Therefore, when the amount of bone from the maxillary sinus sufficient, the MIA can be selected with a larger angle implantation.

In summary, the greater the thickness of the cortical bone in the maxillary posterior region of skeletal class II malocclusion, the greater the thickness of the cortical bone. The larger the tilt angle is, the thicker the cortical bone is obtained from the alveolar crest. It is advisable to choose a small angle $\left(45^{\circ}-60^{\circ}\right)$ to implant a MIA or to select a slightly longer micro-implant at a location near the alveolar crest (near the alveolar crest $4 \mathrm{~mm}$ ). In the case of not touching the maxillary sinus, you can choose to stay away from the alveolar crest site implantation, in order to obtain greater bone cortical thickness in order to facilitate the stability of microscrew implant.

LI, S. F.; XU, F. Y.; XUE, M. R.; WU, X. P.; PARK, H. S. \& BING, L. Seguridad en el micro-implante de anclaje: Espesor del hueso cortical en la región posterior del maxilar en maloclusión de clase esquelética II. Int. J. Morphol., 36 (3):1002-1006, 2018.

RESUMEN: La medición del grosor del hueso cortical y del ángulo de implantación en la región posterior del maxilar por tomografía computarizada de haz cónico (TCHC) se utilizó para proporcionar una referencia para la implantación y el anclaje seguros de un Micro-Implante de Anclaje (MIA) en la maloclusión de clase esquelética tipo II. Veinte muestras de imágenes de TCHC fueron obtenidas de pacientes de ortodoncia (12-40 años) en el Hospital Estomatológico de la Universidad Médica de Shanxi. Se midió el grosor del hueso cortical a $45^{\circ}, 60^{\circ}$ y $90^{\circ}$ de la cresta alveolar, encontrándose a $4 \mathrm{~mm}, 6 \mathrm{~mm}$ y $8 \mathrm{~mm}$, respectivamente. Se utilizó el software estadístico SPSS 17.0 para analizar los datos, y se compa- raron con los métodos ANOVA y LSD de un factor. Hubo una diferencia significativa en el grosor del hueso cortical obtenido al implantar el MIA a la misma altura en diferentes ángulos $(\mathrm{P}<0,05)$. Cuanto mayor es el ángulo de inclinación del MIA implantado, más grueso es el hueso cortical. También, cuanto más alto es el sitio del implante, más grueso es el grosor del hueso cortical. Finalmente, cuanto mayor sea el grosor del hueso cortical en la región posterior del maxilar, en la maloclusión de clase esquelética tipo II, mayor será el grosor del hueso cortical.

PALABRAS CLAVE: Ortodoncia; Maloclusión clase esquelética II; Hueso cortical; Micro-Implante de Anclaje; Ángulo de implantación; Tomografía Computarizada de Haz Cónico

\section{REFERENCES}

Antoszewska-Smith, J.; Sarul, M.; Lyczek, J.; Konopka, T. \& Kawala, B. Effectiveness of orthodontic miniscrew implants in anchorage reinforcement during en-masse retraction: A systematic review and meta-analysis. Am. J. Orthod. Dentofacial Orthop., 151(3):440-55, 2017.

Duran, G. S.; Görgülü, S. \& Dindaroglu, F. Three-dimensional analysis of tooth movements after palatal miniscrew-supported molar distalization. Am. J. Orthod. Dentofacial Orthop., 150(1):188-97, 2015.

Gandhi, V.; Mehta, F. \& Joshi, H. Treatment of class II malocclusion and impacted canines with two-phase orthodontic treatment. Contemp. Clin. Dent., 8(1):161-6, 2017.

Jasoria, G.; Naik, V. R.; Manchanda, M.; Kalra, A. \& Pai, V. Comparison between drill and drill free screws as a source of rigid orthodontic anchorage: a prospective clinical study. Int. J. Orthod. Milwaukee, 24(3):51-7, 2013.

Kalarickal, B. Group distal movement of teeth using Micro-ScrewImplant Anchorage-A case report. J. Clin. Diagn. Res., 8(5):ZD269, 2014.

Khan, B. I.; Singaraju, G. S.; Mandava, P.; Reddy, G. V.; Nettam, V. \& Bhavikati, V. N. Comparison of anchorage pattern under two types of orthodontic mini- implant loading during retraction in type a anchorage cases. J. Clin. Diagn. Res., 10(10):ZC98-102, 2016.

Laursen, M. G.; Melsen, B. \& Cattaneo, P. M. An evaluation of insertion sites for mini-implants: a micro - CT study of human autopsy material. Angle Orthod., 83(2):222-9, 2013.

Lee, J.; Miyazawa, K.; Tabuchi, M.; Sato, T.; Kawaguchi, M. \& Goto, S. Effectiveness of en-masse retraction using midpalatal miniscrews and a modified transpalatal arch: Treatment duration and dentoskeletal changes. Korean J. Orthod., 44(2):88-95, 2014.

Lee, R. J.; Moon, W. \& Hong, C. Effects of monocortical and bicortical mini-implant anchorage on bone-borne palatal expansion using finite element analysis. Am. J. Orthod. Dentofacial Orthop., 151(5):88797, 2017.

Maino, G. B.; Maino, G.; Dalessandri, D. \& Paganelli, C. Orthodontic correction of malpositioned teeth before restorative treatment: efficiency improvement using Temporary Anchorage Devices (TADs). Orthod. Fr, 87(4):367-73, 2016.

Melsen, B.; Huja, S. S.; Chien, H. H. \& Dalstra, M. Alveolar bone preservation subsequent to miniscrew implant placement in a canine model. Orthod. Craniofac. Res., 18(2):77-85, 2015.

Ono, A.; Motoyoshi, M. \& Shimizu, N. Cortical bone thickness in the buccal posterior region for orthodontic mini-implants. Int. J. Oral Maxillofac. Surg., 37(4):334-40, 2008. 
LI, S. F.; XU, F. Y.; XUE, M. R.; WU, X. P.; PARK, H. S. \& BING, L. Micro-implanted-anchorage safety: cortical bone thickness in the maxillary posterior region of skeletal class II malocclusion. Int. J. Morphol., 36(3):1002-1006, 2018.

Sivakumar, I. \& Sivakumar, A. Intrusion of an overerupted molar using orthodontic miniscrew implant: A preprosthodontic therapy. Contemp. Clin. Dent., 5(3):422-4, 2014.

Tenenbaum, H. \& Tenenbaum, M. A clinical study of the width of the attached gingiva in the deciduous, transitional and permanent dentitions. J. Clin. Periodontol., 13(4):270-5, 1986.

Topouzelis, N. \& Tsaousoglou, P. Clinical factors correlated with the success rate of miniscrews in orthodontic treatment. Int. J. Oral Sci.,4(1):3844, 2012.

Wilmes, B.; Su, Y. Y. \& Drescher, D. Insertion angle impact on primary stability of orthodontic mini-implants. Angle Orthod., 78(6):1065-70, 2008.

Wu, X. P.; Huan, J.; Liu, H. Y.; Xue, M. R. \& Li, B. Morphological characteristics of the cranial base of Early Angle's Class II Division 1 malocclusion in permanent teeth. Int. J. Morphol., 35(2):589-95, 2017.
Corresponding author:

Li Bing \& Hyo-Sang Park

\author{
Li Bing \\ Stomatology Hospital \\ Shanxi Medical University \\ 63 XinjianRoad \\ Taiyuan 030001 \\ CHINA
}

Email: libing-1975@163.com

Hyo-Sang Park

Department of Orthodontics, School of Dentistry

Kyungpook National University

188-2, Samduk 2-Ga, Jung-Gu

Daegu

KOREA

E-mail:parkhs@knu.ac.kr

Received:10-01-2018

Accepted: 29-03-2018 